\section{Variasi Anatomi Pola Percabangan Arcus aorta}

\author{
Handy Winata \\ Departemen Anatomi, Fakultas Kedokteran dan Ilmu Kesehatan, Universitas Kristen Krida \\ Wacana, Jakarta, Indonesia. \\ Alamat k orespondensi : handy.winata@ukrida.ac.id
}

\begin{abstract}
Abstrak
Arcus aorta merupakan bagian dari pars thoracica aorta yang terletak di mediastinum superior, berfungsi untuk membawa darah beroksigen ke seluruh bagian tubuh dalam peredaran sistemik. Dari lima studi yang berlainan, semua menunjukkan variasi pola percabangan arcus aorta. Artikel ini membahas variasi pola percabangan arcus aorta menggunakan klasifikasi Natsis. Variasi yang paling banyak ditemukan pada studi ini adalah tipe I dan tipe II.
\end{abstract}

Kata kunci: Arcus aorta, pola percabangan, variasi anatomi.

\section{Anatomical variations of the Branching Pattern of Arcus aorta}

\begin{abstract}
Aortic arch is part of the pars thoracic aorta, located in the superior mediastinum. Its function is to carry oxygenated blood to all parts of the body in systemic circulation. From five different studies, all of them showed variations of the aortic arch branching patterns. This article discusses the variation of aortic arch branching patterns using the Natsis classification. The study found that the variations in the branching pattern are mainly of type I and type II.
\end{abstract}

Keywords: Arcus aorta, anatomy variation, branching pattern

\section{Pendahuluan}

Variasi percabangan pada arcus aorta merupakan salah satu penyebab kematian yang utama pada negara berkembang. ${ }^{1,2}$ Arcus aorta merupakan pembuluh besar yang melengkung dari aorta ascendens, yang berasal dari sebelah posterior articulatio sternocostalis dextra setinggi angulus sternum dan setinggi vertebra thoracal kedua. ${ }^{3,4}$ Arcus aorta terletak di mediastinum superior. Cabang pertama arcus aorta adalah truncus brachiocephalica yang merupakan cabang terbesar dari ketiga cabang arcus aorta. Pada tepi atas sendi sternoclavicularis dextra, bercabang menjadi arteri carotis communis dextra dan arteri subclavia dextra yang memperdarahi sisi kanan kepala, leher dan extremitas superior dextra. Cabang kedua arcus aorta yaitu arteri carotis communis sinistra yang memperdarahi sisi kiri kepala dan leher. Cabang ketiga yaitu arteri subclavia sinistra yang memperdarahi extremitas superior sinistra. Pars thoracica aorta dapat dibagi menjadi aorta ascendens, arcus aorta, dan aorta descendens. Tiga cabang muncul dari batas superior arcus aorta dan pada pangkalnya, ketiganya disilang di sebelah anterior oleh vena brachiocephalica sinistra. Normalnya, letak truncus brachiocephalica berada pada bagian kanan linea midvertebralis dan letak dari arteri carotis communis sinistra dan arteri subclavia sinistra berada pada bagian kiri línea midvertebralis. ${ }^{5-10}$ 


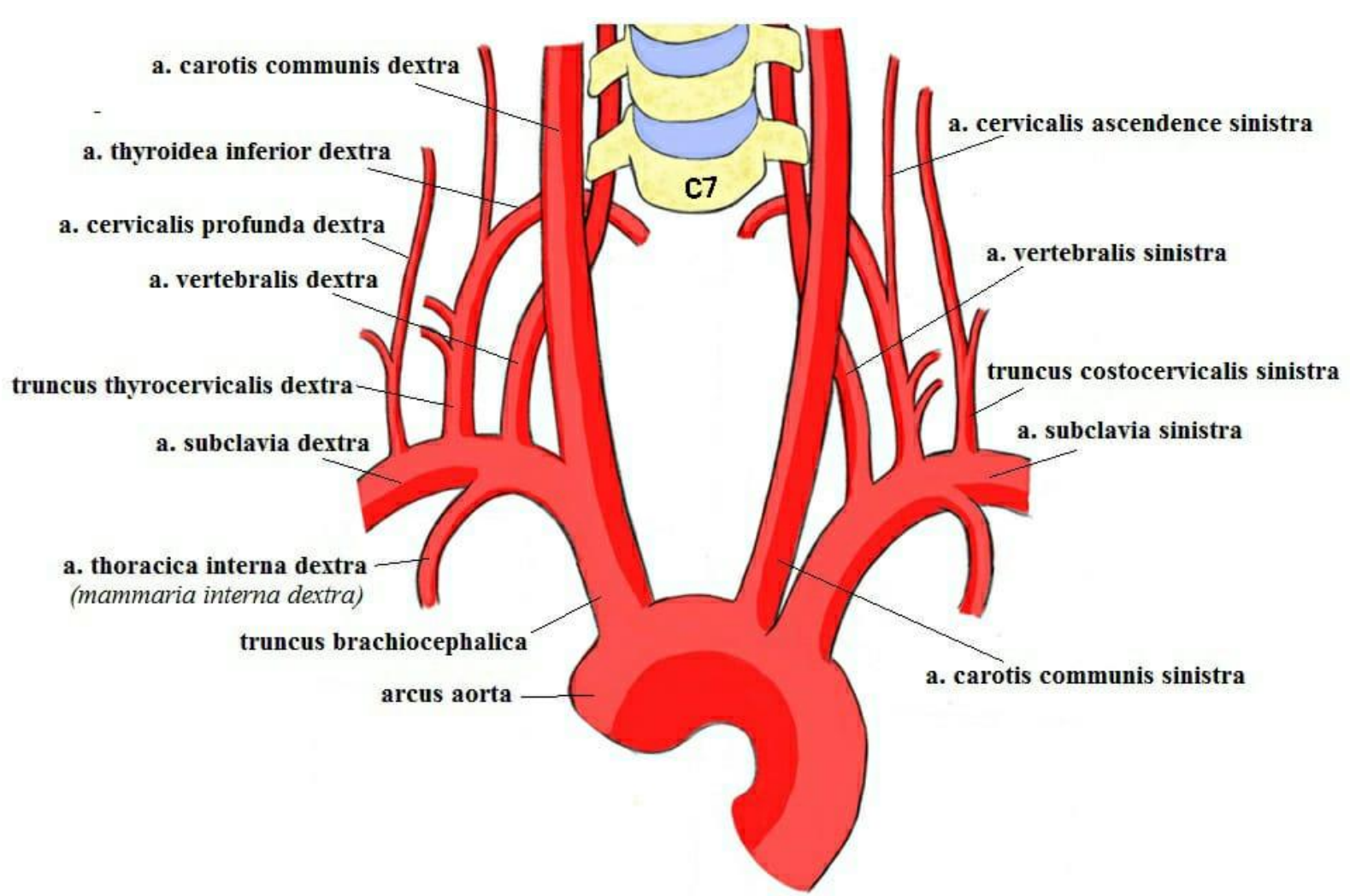

Gambar 1. Arcus aorta dan Percabangannya

Beberapa studi melaporkan bahwa terdapat variasi-variasi dari percabangan arcus aorta. Prevalensi tersebut bervariasi antara 1-2\% dari semua populasi. ${ }^{12,13}$ Variasi ini dapat terjadi akibat dari perubahan perkembangan ketika masa embrio yang berlangsung pada minggu ketiga gestasi. Mayoritas dari variasi-variasi ini biasanya asimptomatik, tetapi beberapa kasus dapat menyebabkan dispneu, disfagia karena tertekannya esofagus, ${ }^{13,14}$ misinterpretasi dari pemeriksaan radiologi dan menimbulkan komplikasi pada pembedahan leher dan thorax. ${ }^{14}$ Menurut klasifikasi Natsis, variasi dari arcus aorta berdasarkan tipe pola percabangannya dibagi menjadi 8 tipe yaitu: ${ }^{15}$

1. Tipe I atau normal mempunyai pola

percabangan dengan tiga cabang yaitu truncus brachiocephalica, arteri carotis communis sinistra, dan arteri subclavia sinistra.

2. Tipe II, arcus aorta dengan dua cabang yaitu truncus brachiocephalica dan arteri subclavia sinistra.

3. Tipe III, arcus aorta dengan empat cabang yaitu truncus brachiocephalica, arteri carotis communis kiri, arteri vertebralis kiri dan arteri subclavia sinistra

4. Tipe IV dengan tiga cabang, cabang pertama yaitu arteri subclavia dextra, truncus yang bercabang menjadi arteri carotis communis sinistra dan dextra, dan cabang ketiga yaitu arteri subclavia sinistra.

5. Tipe $\mathrm{V}$ mempunyai tiga cabang yaitu truncus yang bercabang menjadi arteri carotis communis dextra dan sinista, cabang kedua arteri subclavia sinistra dan cabang ketiga arteri subclavia dextra.

6. Tipe VI mempunyai dua cabang yaitu truncus untuk arteri carotis communis dextra dan sinistra, dan truncus untuk arteri subclavia dextra dan sinistra.

7. Tipe VII mempunya 4 cabang yaitu arteri subclavia dextra, arteri carotis communis dextra, arteri subclavia sinistra dan arteri carotis communis sinistra.

8. Tipe VIII mempunyai empat cabang yaitu truncus brachiocephalica, arteri thyroidea ima, arteri carotis communis sinistra dan arteri subclavia sinistra 


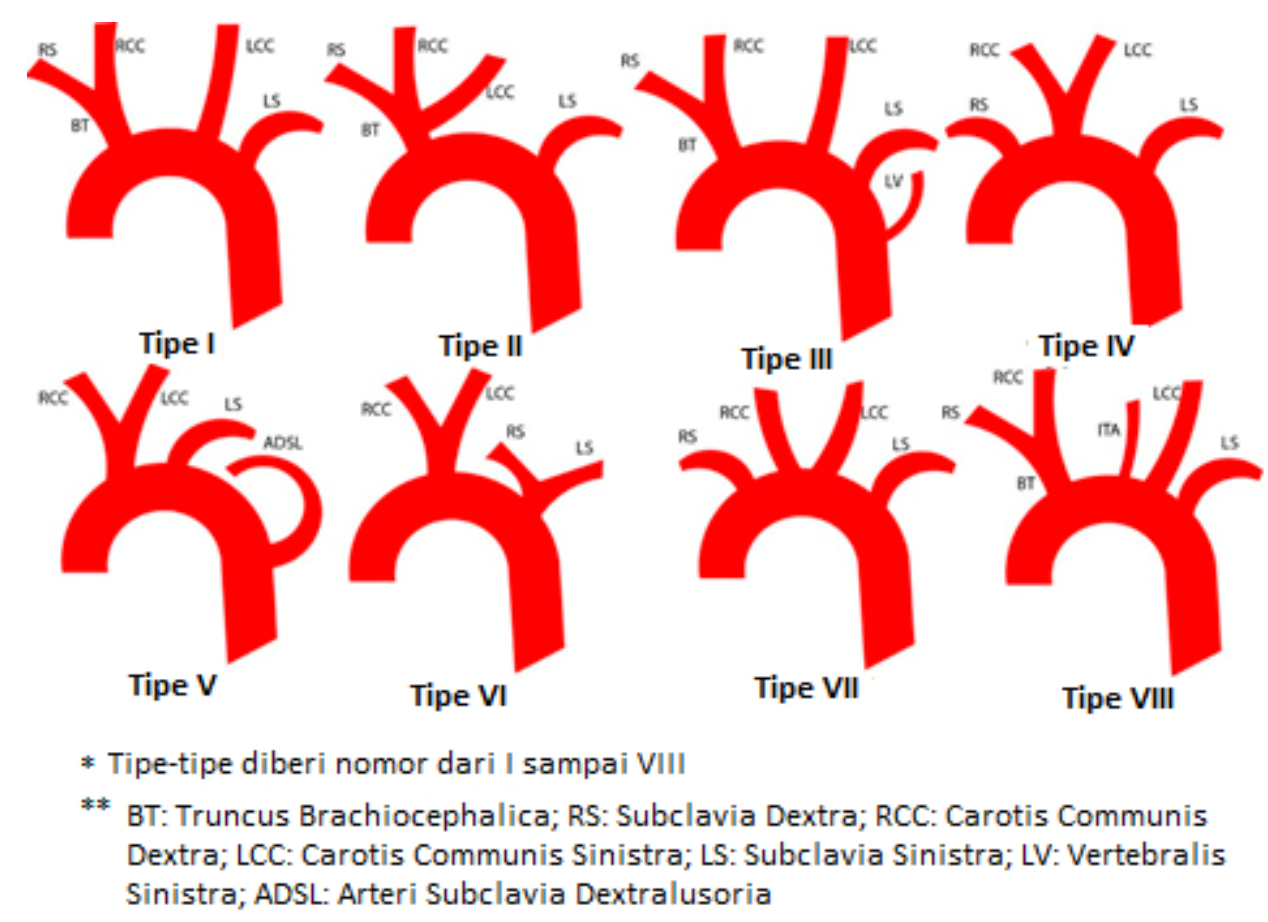

Gambar 2. Klasifikasi Variasi Arcus aorta menurut Natsis ${ }^{16}$ (gambar digunakan dengan ijin)

\section{Beberapa Studi Variasi Percabangan Arcus aorta}

Dari beberapa literatur didapatkan beberapa variasi dari percabangan arcus aorta.

\section{Studi Kasus 1}

Studi kasus dengan 1001 subjek yang terdiri dari 482 perempuan dan 519 laki-laki dianalisa menggunakan 64-slice Computed Tomography Angiography (CTA), ditemukan pada 853 subjek $(85,2 \%)$ mempunyai pola percabangan arcus aorta normal sedangkan 147 subjek $(14,7 \%)$ mempunyai pola variasi percabangan arcus aorta. Pada satu subjek $(0,1 \%)$ ditemukan adanya arcus aorta kanan dengan pola yang paling umum yaitu arteri subclavia sinistra muncul dari percabangan terakhir arcus aorta kanan melintasi dinding posterior oesophagus. Variasi anatomi yang digunakan untuk klasifikasi pada studi kasus ini menggunakan variasi anatomi menurut Natsis. Variasi anatomi arcus aorta tipe 2 ditemukan pada 78 subjek $(7,8 \%)$ yang merupakan variasi anatomi terbanyak. Variasi anatomi arcus aorta tipe 3 ditemukan pada 51 subjek $(5,1 \%) .{ }^{17}$
Tipe-tipe lain mempunyai prevalensi yang lebih sedikit. Tipe 4 ditemukan pada 2 subjek $(0,2 \%)$ dan tipe 7 pada 7 subjek $(0,7 \%)$ sedangkan tipe 5, 6 dan 8 tidak ditemukan pada subjek dalam studi kasus ini. Hasil dari observasi pada populasi dengan tipe 4 , tidak ditemukan efek pola percabangan tersebut terhadap kadar oksigen pada otak namun berkaitan dengan kelainan kardiovaskular kongenital. Tipe 7 termasuk dalam tipe variasi yang jarang ditemukan dan tidak terlihat secara klinis. Selain itu, terdapat satu subjek $(0,1 \%)$ dengan tipe arcus aorta yang tidak dapat diklasifikasikan dalam klasifikasi menurut Natsis yaitu arcus aorta dengan tiga cabang yaitu arteri subclavia dextra, arteri communis carotis dextra, dan truncus brachiocephalica sinistra dengan cabang arteri carotis communis sinistra dan arteri subclavia sinistra. Pada 7 subjek $(0,7 \%)$ ditemukan arteri subclavia dextra abberant dengan empat cabang yaitu arteri carotis communis dextra, arteri carotis communis sinistra, arteri subclavia sinistra, dan arteri subclavia dextra. Pada 1 subjek $(0,1 \%)$ ditemukan adanya dua arteri vertebralis sinistra yang berasal dari percabangan langsung arcus aorta. ${ }^{17}$ 


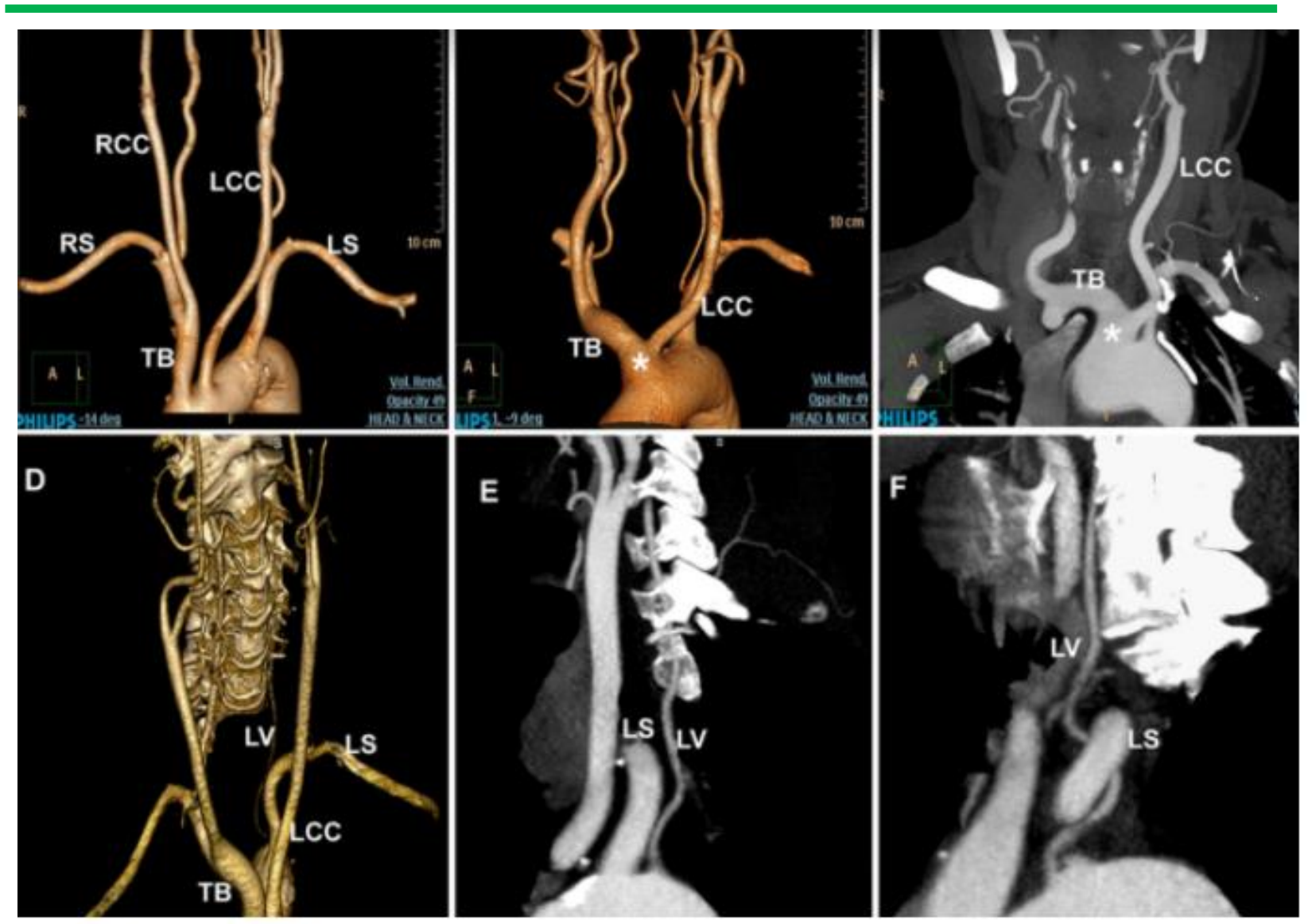

* RCC: Carotis Communis Dextra; LCC: Carotis Communis Sinistra; LS: Subclavia Sinistra; RS: Subclavia Dextra; TB:Truncus Brachiocephalica

Gambar 3. Variasi Arcus aorta pada 64-slice CTA ${ }^{17 \text { (gambar digunakan dengan ijin) }}$

\section{Studi Kasus 2}

Pada studi kasus dengan 500 subjek, terdiri dari 209 perempuan dan 291 laki-laki dianalisa dengan menggunakan CTA, ditemukan pada 306 subjek $(61,2 \%)$ mempunyai pola percabangan arcus aorta normal yaitu tipe 1 sedangkan 194 subjek lainnya $(38,8 \%)$ mempunyai pola variasi pola percabangan arcus aorta. Klasifikasi tipe variasi anatomi pada studi kasus ini berbeda dengan klasifikasi Natsis. Tipe 1 atau tipe normal yang dimiliki sebagian besar manusia dengan pola percabangan truncus brachiocephalica, arteri carotis communis sinistra, dan arteri subclavia sinistra, ditemukan pada 182 laki-laki $(36,4 \%)$ dan 124 perempuan $(24,8 \%)$. Tipe 2 dengan pola percabangan dua cabang utama dari arcus aorta yaitu truncus communis yang bercabang menjadi truncus brachiocephalica dan arteri communis carotis sinistra dan cabang kedua yaitu arteri subclavia sinistra. Tipe 2 ini merupakan variasi anatomi terbanyak yang ditemukan pada 156 subjek $(31,2 \%)$, terdiri dari 88 laki-laki $(17,6 \%)$ dan 68 perempuan $(13,6 \%) \cdot{ }^{18}$

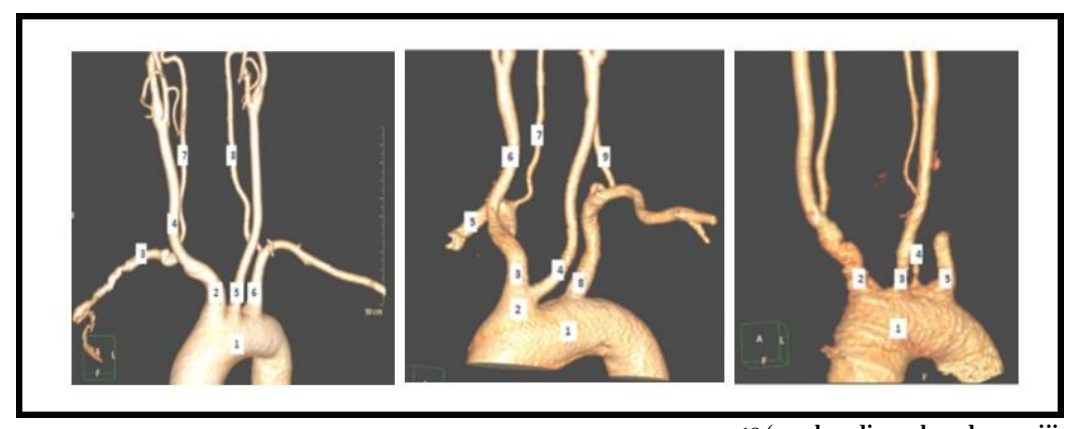

Gambar 4. Variasi Anatomi Tipe 1, 2, 4a, dengan CTA ${ }^{18 \text { (gambar digunakan dengan ijin) }}$ 
Tipe III mempunyai dua cabang dari arcus aorta yaitu truncus brachiocephalica dan truncus yang bercabang menjadi arteri carotis communis sinistra dan arteri subclavia sinistra yang ditemukan pada satu subjek laki-laki $(0,2 \%)$. Tipe 4 yang mempunyai arteri vertebralis sinistra yang bercabang langsung dari arcus aorta ditemukan pada 30 subjek (6\%) terdiri dari 14 laki-laki $(2,8 \%)$ dan 16 perempuan $(3,2 \%)$. Tipe ini dibagi menjadi empat subtype dengan tipe terbanyak yaitu $4 \mathrm{a}$ dengan arteri vertebralis bercabang diantara arteri carotis communis sinistra dan arteri subclavia sinistra yang didapatkan pada 22 subjek $(4,4 \%)$ terdiri dari 9 laki-laki $(1,8 \%)$ dan 13 perempuan $(2,6 \%)$, $4 \mathrm{~b}$ dengan arteri vertebralis terletak diantara truncus communis dan arteri subclavia sinistra yang didapatkan pada 6 subjek $(1,2 \%)$ terdiri dari 4 laki-laki $(0,8 \%)$ dan 2 perempuan $(0,4 \%), 4 \mathrm{c}$ dengan arteri vertebralis terletak di dorsal dari arteri subclavia yang ditemukan pada satu subjek perempuan, 4d dengan arteri vertebralis terletak di distal dari arteri subclavia sinistra yang ditemukan pada satu subjek laki-laki. Tipe 5 dibagi menjadi dua subtype yaitu tipe 5a dengan tiga cabang arcus aorta: truncus brachiocephalica, arteri carotis communis sinistra, dan truncus communis yang bercabang menjadi arteri vertebralis sinistra dan arteri subclavia sinistra yang didapatkan pada satu subjek laki-laki $(0,2 \%)$ dan 5 b dengan dua cabang arcus aorta: cabang pertama yaitu truncus yang bercabang menjadi truncus brachiocephalica dan arteri carotis communis sinistra dan cabang kedua yaitu truncus yang bercabang menjadi arteri vertebralis sinistra dan arteri subclavia sinistra yang ditemukan pada satu subjek laki-laki $(0,2 \%)$. Tipe 6 dengan adanya arteri subclavia dextra sebagai cabang langsung dari arcus aorta atau dikenal sebagi arteri subclavia dextra abberant dibagi menjadi dua subtype yaitu 6a dengan empat cabang pada arcus aorta yaitu arteri carotis communis dextra, arteri carotis communis sinistra, arteri subclavia sinistra dan arteri subclavia dextra yang ditemukan pada dua subjek $(0,4 \%)$ terdiri dari satu subjek laki-laki $(0,2 \%)$ dan satu subjek perempuan $(0,2 \%)$ dan $6 \mathrm{~b}$ dengan tiga cabang pada arcus aorta yaitu truncus bicarotis yang bercabang menjadi arteri carotis communis dextra dan sinistra, arteri subclavia sinistra dan arteri subclavia dextra yang ditemukan pada tiga subjek lakilaki $(0,6 \%){ }^{18}$

\section{Studi Kasus 3}

Sebanyak 633 pasien Yunani, terdiri dari 447 laki-laki dan 186 perempuan pada rentang usia 19-79 tahun diobservasi dengan menggunakan Digital Subtraction Angiography (DSA) via arteri femoralis. Klasifikasi tipe variasi anatomi pola percabangan arcus aorta pada studi kasus ini menggunakan klasifikasi Natsis. Tipe 1 atau tipe normal, ditemukan pada 527 subjek (83\%) dengan 375 laki-laki dan 152 perempuan. Tipe 2, pola kedua terbanyak, ditemukan pada 96 subjek (15\%), terdiri dari 67 laki-laki dan 29 perempuan. Tipe 3, ditemukan pada 5 subjek $(0,79 \%)$ pada 2 laki-laki dan 3 perempuan. Tipe 4 dengan tiga cabang, ditemukan pada 1 subjek perempuan $(0,16 \%)$, tipe 5 dan 6 masing-masing ditemukan pada 1 subjek laki-laki $(0,16 \%)$. Tipe 7 ditemukan pada 1 subjek perempuan $(0,16 \%)$. Tipe VIII terdapat pada 1 subjek laki-laki $(0,16 \%) .{ }^{15}$

\section{Studi Kasus 4}

Studi dilakukan pada 361 subjek populasi Peru, dengan menggunakan Multislice $C T$ Spiral Angiography (MSCTA), dengan menggunakan klasifikasi Natsis. Terdapat variasi yang berbeda dari cabang arcus aorta, dengan 3 tipe baru. Tipe 1 atau tipe normal adalah yang terbanyak berjumlah 275 subjek $(78,12 \%)$, lalu tipe 2 sebanyak 41 subjek $(11,36 \%)$, tipe IX sebanyak 25 subjek $(6,93 \%)$, tipe 3 sebanyak 8 subjek $(2,22 \%)$, tipe 5 sebanyak 3 subjek $(0,83 \%)$ kemudian masingmasing tipe 10 dan 11 sebanyak 1 subjek. Tidak ditemukan variasi tipe $4,6,7$ dan 8 dalam populasi ini. ${ }^{16}$

\section{Studi Kasus 5}

Studi kasus dengan 52 subjek kadaver yang dinding toraksnya dibuka dengan menggunting melewati costochondral junction dan menghilangkan sternum dan kartilago kosta. Paru-paru dihilangkan, vena cava superior dan vena brachiocephalica dibersihkan, dan pericardium dibuka unqtuk mengekspos aorta ascendens. Saraf dan jaringan lemak fibrosa dihilangkan untuk mengklarifikasi cabang arcus aorta dan variasi 
pola percabangannya. Pada 33 kadaver (63.5\%), arcus aorta menunjukkan pola percabangan klasik dari truncus brachiocephalica, arteri carotis communis sinistra, arteri subclavia sinistra. 19 kadaver menunjukkan variasi pola percabangan dimana sepuluh kadavernya memiliki 2 cabang; arteri subclavia sinistra dan truncus communis yang akan bercabang menjadi truncus brachiocephalica dan arteri carotis communis sinistra. ${ }^{19}$ Delapan kadaver memiliki empat cabang; truncus brachiocephalica, arteri carotis communis sinistra, arteri vertebralis sinistra, arteri subclavia sinistra, dan satu kadaver memiliki tiga cabang; truncus communis, arteri vertebralis sinistra, dan arteri subclavia sinistra. ${ }^{19}$ Pada 50 kadaver, titik asal truncus brachiocephalica berada di kanan garis midvertebralis, tetapi pada dua kadaver (3.8\%), titik asal truncus brachiocephalica berada di kiri garis midvertebralis. Variasi berdasarkan klasifikasi Natsis, variasi anatomi tipe 1 sebanyak 33 kadaver $(63.5 \%)$ dan tipe 3 sebanyak 8 kadaver (15.4\%). Terdapat 2 kelompok yang tidak sesuai yaitu yang memiliki 2 cabang; arteri subclavia sinistra dan truncus communis dan 3 cabang; truncus communis, arteri vertebralis sinistra, dan arteri subclavia sinistra. ${ }^{19}$

Tabel 1. Prevalensi Variasi Tipe Arcus aorta ${ }^{16}$ (with permission)

\begin{tabular}{ccccc}
\hline Tipe & Laki-laki & Perempuan & Total & Persentase \\
\hline Tipe I & 152 & 130 & 282 & 78.12 \\
Tipe II & 23 & 18 & 41 & 11.36 \\
Tipe III & 6 & 2 & 8 & 2.22 \\
Tipe V & 0 & 3 & 3 & 0.83 \\
Tipe IX & 12 & 13 & 25 & 6.93 \\
Tipe X & 1 & 0 & 1 & 0.28 \\
Tipe XI & 0 & 1 & 1 & 0.28 \\
\hline Total & $\mathbf{1 9 4}$ & $\mathbf{1 6 7}$ & $\mathbf{3 6 1}$ & $\mathbf{1 0 0}$ \\
\hline
\end{tabular}

\section{Pembahasan}

Lima studi kasus di atas melakukan observasi terhadap variasi dari pola percabangan arcus aorta. Pembuluh darah pada arcus aorta yaitu truncus brachiocephalica, arteri carotis communis sinistra, arteri carotis communis dextra, arteri subclavia sinistra, arteri subclavia dextra, dan arteri vertebralis sinistra mempunyai variasi percabangan yang berbeda-beda seperti jumlah dan letak cabang pembuluh darah dari arcus aorta. Kelima studi kasus menunjukkan adanya variasi dari arcus aorta pada total subjek yang diteliti dengan persentase yang berbeda tiap studi. Dari variasivariasi ini, lima studi kasus menunjukan tipe 1 atau normal yaitu pola percabangan truncus brachiocephalica, arteri carotis communis sinistra, dan arteri subclavia sinistra mempunyai prevalensi paling banyak dimiliki oleh subjek. Variasi kedua yang paling banyak adalah tipe 2 dengan pola percabangan truncus brachiocephalica dan arteri subclavia sinistra.

Pada studi kasus Ergun et al, variasi ketiga paling banyak adalah tipe 3 yaitu truncus brachiocephalica, arteri carotis communis kiri, arteri vertebralis kiri dan arteri subclavia sinistra dengan persentase $5,1 \%$. Hal tersebut mempunyai persamaan dengan studi kasus 3 dengan persentase $0,79 \%$ dan studi kasus 5 dengan persentase $15,4 \%$ sedangkan variasi ketiga paling banyak pada studi kasus 2 adalah tipe yaitu arteri vertebralis yang bercabang langsung pada arcus aorta dengan persentase 4,4\%. Pada studi kasus 4, variasi ketiga paling banyak adalah tipe 9 dan keempat paling banyak adalah tipe 3 dengan persentase 2,2\%. Hal ini dapat disebabkan karena jumlah subjek yang diteliti berbeda.

Pada studi kasus Mustafa et al yang membandingkan prevalensi variasi arcus aorta berdasarkan jenis kelamin, hasilnya menunjukkan tidak ada perbedaan yang signifikan antara laki-laki dan perempuan. Hal ini sesuai dengan studi kasus oleh Karacan et al yang menunjukkan persentase insiden pola percabangan arcus aorta antara laki-laki dan perempuan sama yaitu $20 \%$ dengan $22,1 \%$. Variasi dari pola percabangan arcus aorta mempunyai kepentingan dalam prosedur bedah untuk intervensi vascular sehingga dapat 
memberikan tindakan dengan aman sesuai pada pola percabangan pasien tersebut. ${ }^{20}$

\section{Penutup}

Pada lima studi kasus di atas, ditemukan variasi pada arcus aorta namun perbedaan terhadap acuan terjadinya suatu variasi juga didapatkan pada studi-studi di atas. Salah satunya mengenai kelainan letak dari cabang arcus aorta yaitu truncus brachiocephalica yang berada di kiri garis midvertebralis. Variasi lain yaitu berdasarkan jumlah dari cabang arcus aorta. Berdasarkan klasifikasi Natsis, ditemukan variasi paling banyak pertama adalah tipe 1 dan yang kedua paling banyak adalah tipe 2. Berdasarkan studi kasus Mustafa et al, laki-laki dan perempuan dengan variasi anatomi arcus aorta mempunyai prevalensi sama. Pada tinjauan pustaka ini yang diambil dari lima studi dengan populasi dan jenis kelamin yang berbeda, menunjukkan adanya variasi terhadap subjek mereka.

\section{Ucapan Terima Kasih}

Andreas Billy dari FK Ukrida yang telah menghubungi pihak-pihak terkait dalam pengurusan ijin penggunaan gambar di naskah ini.

\section{Daftar Pustaka}

1. Tsamis A, Krawiec JT, Vorp DA. Elastin and collagen fibre microstructure of the human aorta in ageing and disease: a review. $J$ $R$ Soc Interface. 2013;10:20121004.

2. Bottle A, Mariscalco G, Shaw MA, Benedetto U, Saratzis A, Mariani S, et al. Unwarranted variation in the quality of car for patients with diseases of the thorasic aorta. J AM Heart Assoc. 2017;6:3004913.

3. Moore KL, Dalley AF. Anatomi berorientasi klinik. Edisi Kelima. Jakarta: Erlangga; 2013.

4. Tao L, Kendall K, Elizabeth H, William H. Organ system, clinical science. Jilid satu. Karisma; 2016.

5. Gunardi S, Liem IK, penyunting. Buku ajar anatomi Sobotta. Edisi pertama. Indonesia: Elsevier; 2015.

6. Gunardi S, Saputra L, penyunting. Anatomi klinik. Edisi kedua. Jilid satu. Binarupa Aksara; 2012.
7. Patil A, Ambli SK. Transesophageal echocardiography evaluation of the aorta arch branches. Ann Card Anaesth. 2018;21:53-6.

8. Faiz O, Moffat D. At a Glance anatomi. Jakarta: Erlangga; 2014.

9. Basmajian JV, Slonecker CE. Grant Metode anatomi berorientasi pada klinik. Edisi kesebelas. Jilid Satu. Binarupa Aksara; 1995.

10. Drake RL, Vogl W, Mitchell AWM. Gray Dasar-dasar anatomi. Singapuro: Elsevier: 2013.

11. Netter. Normal and anomalous origins of common carotid and vertebral arteries. Diakses dari https://www.netterimages.com/branchesof-the-aorta-labeled-runge-cardiology-1ecardiology-hypertension-frank-h-netter13922.html, pada tanggal 8 Maret 2018.

12. Priya $S$, Thomas $R$, Nagpal $P$, Sharma A, Steigner M. Congenital anomalies of the aortic arch. Cardiovasc Diagn Ther. 2018; 8(suppl 1):S26-S44.

13. Noguchi K, Hori D, Nomura Y, Tanaka H. Double aortic arch in an adult. Interactive Cardiovascular and Thorasic Surgery. 2012;14: 900-2.

14. Rea G, Valente T, Iaselli F, Urraro F, Izzo A, Sica G, et al. Multi-detector computed tomography in the evaluation of variants and anomalies of aortic arch and its branching pattern. IJAE. 2014; 3(119): 180-92.

15. Natsis KI, Tsitouridis IA, Didagelos MV, Fillipidis AA, Vlasis KG, Tsikaras PD. Anatomical variations in the branches of the human aortic arch in 633 angiographies: clinical significance and literature review. Surg Radiol Anat. 2009; 31(5): 319-23.

16. Huapaya JA, Chavez-Trujillo K, Trelles M, Carbajal RD, Espadin RF. Anatomic variations of the branches of the aortic arch in a Peruvian population. Medwave. 2015 Jul;15(6):e6194

17. Ergun E, Simsek B, Kosar PN, Yilmaz BK, Turgut AT. Anatomical variations in branching patterns of arcus aorta: 64-slice CTA appearance. Surg Radiol Anat. 2013; 35:503-9.

18. Mustafa AG, Allouh MZ, Ghaida JHA, AlOmari MH, Mahmoud WA. Branching patterns of the aortic arch: a computed 
tomography angiography based study. Surg Radiol Anat. 2017; 39: 235-42.

19. Budhiraja V, Rastogi R, Jain V, Bankwar $\mathrm{V}$, Raghuwanshi S. Anatomical variations in the branching patterns of human aortic arch: a cadaveric study from Central India. ISRN Anatomy, 2013 (2013).
20. Karacan A, Turkvatan A, Karacan K. Anatomical variations of aortic arch branching: evaluation with computed tomographic angiography. Cardiology in the Young, 2014; 24:485-9. 